\title{
Periferal İntravenöz Kemoterapi Uygulamasına Yönelik Hemșirelik Yönetimi
}

\author{
${ }^{1}$ Ayşe Özkaraman, ${ }^{2}$ Öznur Usta Yeşilbalkan \\ ${ }^{1}$ Eskişehir Osmangazi Üniversitesi Eskişehir Sağlık Yüksek Okulu, Eskişehir \\ ${ }^{2}$ Ege Üniversitesi Hemşirelik Fakültesi, İç Hastalıkları Hemşireliği Anabilim Dalı, İzmir \\ e-posta:aozaydin26@hotmail.com
}

\begin{abstract}
ÖZET: Kemoterapi ilaçlarının intravenöz (IV) yolla uygulanmasında infiltrasyon ve ekstravazasyon gibi istenmeyen durumların yanı sıra flebit, hava embolisi, kanama ve hematom, enfeksiyon gibi bazı komplikasyonlar da gelişebilmektedir. IV tedavi uygulamalarından sorumlu olan hemşireler uygulama esnasında ne kadar dikkatli davranırlarsa da bu komplikasyonlar hala önlenemeyen bir sorun olarak karşımıza çıkmaktadır. Kemoterapi uygulamasında bilgili ve yetenekli bir hemşire tarafından doğru girişimlerin uygulanması bu komplikasyonların önlenmesinde ve yönetiminde en önemli kontrol edilebilir faktördür.
\end{abstract}

ANAHTAR KELIMMELER: IV kemoterapi tedavisi, komplikasyon, hemşire

\begin{abstract}
Complications which unlikely events such as infiltration, extravasation as well as phlebitis, air embolism, hemorrhage and hematoma, infections may occur in the intravenous administration of chemotherapy drugs. Although nurses who are responsible for intravenous therapy applications how careful being, these complications cannot always be prevented. Implementation of interventions by knowledgeable and skilled nurses in the intravenous chemotherapy towards the prevention and manangement of these complications is the most important factor which can be controlled.
\end{abstract}

KEY WORDS: IV Chemotherapy, complication, nurse

\section{Giriş}

İntravenöz (IV) ilaç tedavisi, ilaç ya da sıvıyı damar içine uygulama yöntemidir ve ilaç uygulama yolları arasında en fazla riski olan yoldur (1). Son y1llarda onkoloji hastalarının sayısının giderek artması ile intravenöz girişim sayısı artmış ve bu alanda hemşirelerin görev ve sorumlulukları da gündeme gelmiștir $(2,3)$. Özellikle kanser hastalarında tekrarlı uygulamalara bağlı olarak IV kemoterapi tedavisinde damar yolunu açmak, açıklığını sürdürmek hem hasta hem de hemşireler için zor bir uygulamadır $(3,4) . \quad \mathrm{Bu}$ nedenle hemşirelerin periferal IV kemoterapi uygulamasını başarılı bir şekilde yürütebilmesi için uzmanlık bilgisi ve yeteneğine sahip uygulamalarında kanıt temelli araştırmalara ve klavuzlara yer vermeleri, ayrıca hastanelerin periferal intravenöz kateter (PIVK) ve kemoterapi uygulamasi, enfeksiyonların önlenmesi ve güvenlik önlemlerini içeren standart uygulama prosedürlerini oluşturmaları oldukça önemlidir (5-13). Hastanın konforunu arttırmak, uygulamayı etkin bir şekilde sürdürmek ve komplikasyonları önlemek amacıyla onkoloji hemşiresi IV giriş yapılacak hastayı değerlendirmeli, ve bilgilendirmeli, IV giriş için uygun malzemeleri hazırlamalı, IV giriş işlemini rehberlerde belirtildiği biçimde yapmalı, IV kateter uygulamasina bağlı gelişebilecek enfeksiyonları önlemek için gerekli önlemleri almalı ve komplikasyon meydana geldiğinde gerekli uygun hemşirelik girişimlerini uygulamalıdır. 


\section{Hasta değerlendirmesi}

Hemşire periferik intravenöz kateter takılacak hastanın; kemoterapi protokolünü, periferal intravenöz kateterin yerleştirileceği bölgeyi ve hastanın genel durumunu değerlendirmelidir. Kemoterapi tedavisinde yer alan ilaçların pH'1, osmoloritesi, yoğunluğu, uygulama hızı ve uygulama süresine göre periferal ya da santral venöz yol tercih edilmektedir. $\mathrm{Bu}$ nedenle hemşirenin öncelikle hastanın kemoterapi protokolünü değerlendirmesi gerekir. Hastanın çocuk, yaşl1, uykulu veya bilişsel algısal bozukluğunun olması IV komplikasyon riskini artıracağ 1 için bu durumlar mutlaka göz önünde bulundurulmalıdır $\quad(8,14) . \quad$ PIVK yerleştiril-meden önce hastanın venleri görülerek ve dokunarak değerlendirilmeli, kateter takilacak venlerin ön kolda bulunan büyük venler olmasına özen gösterilmelidir $(1,8)$.

Kateterin yerleştirilmesinde mümkün oldu-ğunca eklemlere yakın bölgeler, antekübital fossa ya da el sirtında bulunan venler tercih edilmemelidir (7,13-18). Özellikle meme kanserli hastalarda lenfödem varlığında PIVK'lar bu bölgeye yerleştiril-memelidir $\quad(15,16)$. Yapılan değerlendirmenin sonunda komplikasyon gelişme riski yüksek ve PIVK'ın sürekliliği sağlanamayacak ise santral venöz kateterler (SVK) tercih edilmelidir (1).

\section{Hasta eğitimi}

Hastaya kemoterapi tedavisine başlanmadan önce kemoterapinin yan etkileri, komplikasyonları, riskleri, yararları, fizyolojik ve psikolojik etkileri hakkında bilgilendirme yapılmalıdır $(10,19)$. Genellikle sağlık profesyonelleri hastayı kemoterapi tedavisinin toksisiteleri hakkında bilgilendirirken, kemoterapi tedavisinin komplikasyonları hakkında yeterince bilgi verememektedir. Bu durum kemoterapi uygulamasına bağlı olası komplikasyon görülme riskini arttırmaktadır. $\mathrm{Bu}$ nedenle hastalara IV kemoterapi komplikasyonlarının belirti ve bulguları, hemşireyi bilgilendirme, PIVK'ın devamlılığını sağlamak için yazılı materyal ve sözlü eğitimler verilmelidir $(8,19)$.

\section{Malzeme seçimi}

Başarılı bir IV kemoterapi uygulamasında malzemeler, kullanım amacı ve süresi göz önüne alınarak seçilmelidir $(8,10,17,18)$. Özellikle vezikant ilaçların infüzyonunda kelebek set gibi çelik iğneler ven duvarını delip geçerek ilacın damar dışına sızmasına neden olduğu için kullanılmamalıdır. Bunların yerine mümkün olduğunca fleksıbl kateterler tercih edilmelidir (14-17). Kateterin çap1 venin genişliği ile uyumlu olmalı, gönderilecek ilaç/sıvı yoğun ve hızlı ise geniş çaplı kateterler kullanılmalıdır $(18,20)$. Uygulanacak tedavinin süresi alt1 günden fazla olacaksa kisa periferal kateterler yerine santral periferal kateterler kullanılmalıdır

(10).

PIVK yerleştirilmeden önce bölge temizliğinin sağlanması için \%70'lik alkol, tentürdiyot veya alkollü klorheksidin glukonat solüsyonu kullanılmalıdır(10,21, 22). PIVK bölgesinde olası komplikasyonların izlemi için kateterin üzerini kapatmak için transparan bir örtü tercih edilmeli ve iyi sabitlenmelidir $(7,10,13,14,16,23)$.

\section{Periferal intravenöz kateter uygulaması}

Periferal intravenöz kateter yerleştirilmeden önce hastaya yatar ya da oturur pozisyon verilmelidir. Turnike seçilen damarın 5-12 cm üzerinden bağlanmalı ve 2 dakikadan fazla bağlı kalmamasına dikkat edilmelidir. Ön kol damarlarında venöz dolgunluğu sağlamak amaciyla hastadan elini açıp kapatması ve yumruk yapması istenmelidir. İğnenin kesik ucu üstte kalacak şekilde cilde 30-45 ' lik açı ile yerleştirilmeli, daha sonra iğne $3^{\circ}$ ye düşürülerek ven içinde ilerletilmelidir $(1,8)$. Eğer iğne hemen yerleştirilmez ise daha derinlere ilerletilmemelidir, aksi halde ven duvarının delinme ihtimali vardır. Bunun yerine PIVK girişimine son verilerek bir başka venden PIVK girişi yapılmalıdır (7). PIVK takildıktan sonra 
kan gelip gelmediği kontrol edilmeli ve transparan bir örtü ile kapatılarak tespiti sağlam yapılmalıdır. PIVK'lar takıldıktan sonra 72-96 saat kalmalı, daha uzun uygulamalar için kateter çıkartılarak başka bir vene PIVK yerleştirilmelidir $(10,24)$. İnfüzyon için kullanılan setler 24-48 saatte bir değiștirilmelidir (25).Kemoterapiye başlamadan önce kateterin yerinde olup olmadığını kontrol etmek için kateterden 10-20ml salin solüsyon uygulanmalıdır (1,7,13-16). İlaçlar gönderilirken ya bolus şeklinde ya da yer çekimine göre akış hızı ayarlanmalıdır. Özellikle vezikant ilaçların gönderilmesinde ilaç pompaları, pompa alarm verinceye kadar ilacin gönderilmesine devam edeceği ve ekstravazasyon alanı daha çok yaygınlaşacağı için kullanımı önerilmemektedir $(7,14)$. Uygulama esnasinda vezikant ilaçların infüzyon süresi 12-24 saati aşmamalıdır. Aksi takdirde SVK'lar kullanılmalıdır. Vezikant ilaçların bolus uygulamasında yakın gözlemle birlikte, eş zamanlı bir başka sıvı gönderilerek ilaç dilüe edilmelidir $(7,16)$. İnfüzyon bittikten sonra kateterden \%0.09'luk sodyum klorür gönderilerek işlem bitirilmeli (7), kateter ve setler asepsi kurallarına uygun olarak çıkartılmalıdır $(8,10)$. Periferal intravenöz kemoterapi tedavisinin komplikasyonlarını erken fark edebilmek için kateter bölgesi uygulama esnasında ve sonrasında 48 saat süresince İnfüzyon Hemşireleri Topluluğu İnfiltrasyon ve Ekstravazasyon Skalası, İnfüzyon Hemşireleri Topluluğu Flebit skalası kullanılarak izlenmelidir $(7,8,13,14,18$, 26).

\section{İnfeksiyonu önleme}

İntravenöz tedavilere bağlı gelişebilecek komplikasyonları önlemek amacıyla tüm uygulamalarda infeksiyon kontrolüne dikkat edilmesi, işlem öncesi ve sonrası el hijyenine uygun şekilde ellerin yıkanması, uygulanacak prosedürlerin her aşamasında asepsi ve gerektiğinde steril tekniğe uyulması gerekir. $\mathrm{Bu}$ amaçla eldiven, önlük, maske gibi kişisel koruyucu malzemeler kullanılmalıdır $(8,10,11,21)$.

Periferal intravenöz kemoterapiye bağlı gelişen komplikasyonlarının yönetimi

İntravenöz kemoterapi uygulamasına bağl1 olarak infiltrasyon, flebit, ekstravazasyon, hematom, hemoraji, enfeksiyon ve hava embolisi görülmektedir $(10,11,18,25$, 27). PIVK uygulamasina bağl1 Amerika'da y1lda 250.000-500.000 enfeksiyon geliştiği ve bu enfeksiyonlara bağl1 mortalitenin \%12-25 olduğu bildirilirken (28), flebitin IV infüzyon tedavisi alan hastaların \%20-80'nde tedavi sirasinda (17), \%5'nda ise PIVK çıkartıldıktan 24 saat geliştiği bildirilmiştir (29). İnfiltrasyon ve ekstravazasyon insidansında ise kayıt sisteminin yokluğu nedeni ile farklı veriler mevcut olmasına rağmen bildirilen vaka sayılarına göre görülme sıklığı $\% 0.01-7$ olarak rapor edilmiştir $(16,30)$.

Kemoterapi ilaçları damar dișına sızdığında dokuda meydana gelebilecek nekrozun ciddiyetine göre nötralize olanlar, inflamasyona neden olanlar, irritanlar, soyucu olanlar ve vezikantlar olarak siniflandırılmaktadır $(6,12,13)$. Nötralize ilaçların damar dışına sızması sonucu dokuda hasar çok az ya da hiç görülmezken, vezikant ilaçların damar dışına sızmasına bağlı olarak dokuda yaralanmalar ve kayiplar görülebilmektedir. $\mathrm{Bu}$ semptomlar ilacın damar dışına sızmasını takiben birkaç gün ya da hafta içinde ortaya çıkabilmekte ve infüzyon bölgesinde lokal yanma, ağrı, hafif eritem, ciltte soyulma, ülserasyon ve nekroz meydana gelmektedir (31). Ülserasyon ve nekroz gelişen dokuda iyileşme kendiliğinden sağlanamayıp çoğu kez tendon ve nörovasküler yapılarda etkilenmekte ve hastalarda fonksiyon kayıpları görülmektedir (32).

Literatür incelendiğinde kemoterapi uygulamasına bağlı komplikasyonları önlenmeye ve yönetimine yönelik rehberler ve algoritmaların geliştirildiği, araştırmaların yapıldığ 1 görülmektedir ( 7 , 
13-15, 19, 27, 30, 32, 35-39). Hemşireler bu rehber ve kanit temelli uygulamaları hastanın konforu ve güvenliği için kullanmalıdırlar.

Periferal intravenöz kemoterapi tedavisi uygulanan vende infiltrasyon ortaya çıtığında, infüzyon hemen durdurulmalı, gerekirse başka bir yerden tekrar damar yolu açılmalıdır. İlacın infiltre olduğu ekstremite yukarı kaldırılarak, ilacın özelliğine göre 20 dakika sicak-soğuk uygulama yapılmalıdır $(13,27,38)$. Eğer PIVK' in yerleştirildiği vende flebit tespit edilirse kateter çıkartılarak yeri değiştirilmelidir. Uygulama süresince her 96 saatte bir PIVK'in yeri değiștirilmeli, eğer vezikant tedavi sürekli olarak uygulanacak ise PIVK yerine SVK tercih edilmelidir (19).Ekstravazasyon görülmesi durumunda ise farmakolojik ve nonfarmakolojik girişimler uygulanmalıdır (Tablo1) (7, 13-15, 19, 31-39).

\section{Sonuç}

Onkoloji hastalarında periferal intravenöz kemoterapi uygulaması oldukça zor bir uygulamadır. Onkoloji hemşirelerin periferal intravenöz kemoterapi uygulama başarısını arttırmak, komplikasyonları önlemek, hastanın rahat ve konforu için yararlı yaklaşımı belirlemek için, konu hakkında düzenlenen eğitim programlarını, geliştirilen klavuzları ve yapılan kanıt temelli çalışmaları yakından takip etmesi ve uygulamalarında yer vermesi son derece önemlidir.

\section{Tablo 1}

Vezikant İlaçların Ekstravasyonunda Önerilen Girişimler

\begin{tabular}{|c|c|c|}
\hline İlaç & Farmakolojik girişimler & Non-farmakolojik girişimler \\
\hline Nötralize olanlar & $\begin{array}{l}\text { - 1500U/ml Hyaluronidase S.C } \\
\text { yolla ekstravazasyon bölgesine } \\
\text { yapilmalıdır. }\end{array}$ & $\begin{array}{l}\text { - Ekstravazasyonu takiben ilk } 24 \\
\text { saat süresince } 6 \text { saatte bir } 20 \mathrm{dk} \\
\text { süresince sicak uygulama } \\
\text { yapılmalıdır }\end{array}$ \\
\hline İnflamasyon yapanlar & $\begin{array}{l}\text { - Ekstravazasyon bölgesinde } \\
\text { eritem devam ettiği müddetçe } 6 \\
\text { saatte bir \%1'lik } \\
\text { hidrokortizonlu kremler } \\
\text { uygulanmalıdır }\end{array}$ & $\begin{array}{l}\text { - Ekstravazasyonu takiben ilk } 24 \\
\text { saat süresince her } 4 \text { saatte bir } \\
30 \text { dk bölgeye soğuk uygulama } \\
\text { yapılmalıdır. } \\
\text { - İnflamasyon reaksiyonları } \\
\text { azalmaya başladığında } \\
\text { bölgeden rezidüel sıvı1 } \\
\text { uzaklaştırmak için sıcak } \\
\text { uygulama yapılmalıdır. }\end{array}$ \\
\hline $\begin{array}{l}\text { İritanlar } \\
\text { Arsenic trioxide Carboplatin } \\
\text { Etoposide Irinotecan } \\
\text { Teniposide }\end{array}$ & $\begin{array}{l}\text { - Ekstravazasyon bölgesine } 7 \\
\text { gün boyunca } 6 \text { saatte bir } \\
\% 1 \text { 'lik hidro-kortizonlu } \\
\text { kremler uygulanmalıdır }\end{array}$ & $\begin{array}{l}\text { - Ekstravazasyonu takiben ilk } 24 \\
\text { saat her } 4 \text { saatte bir } 30 \text { dk } \\
\text { bölgeye soğuk uygulama yapil- } \\
\text { malıdır. } \\
\text { - İnflamasyon reaksiyonları } \\
\text { azal-maya başladığında ise } \\
\text { rezidüel sıvıı uzaklaştırmak } \\
\text { için sıcak uygulama } \\
\text { yapılmalıdır. }\end{array}$ \\
\hline $\begin{array}{l}\text { Soyucular } \\
\text { Cisplatin Docetaxel Oxaliplatin } \\
\text { Topotecan }\end{array}$ & $\begin{array}{l}\text { - Topotecan dışındaki diğer } \\
\text { ilaçların ekstravazasyonunda } \\
\text { 1500U/ml hyaluronidase S.C. } \\
\text { yolla enjekte edilmelidir. } \\
\text { - Ekstravazasyon bölgesinde } \\
\text { eritem devam ettiği müddetçe } \\
\text { her } 6 \text { saatte bir \%1'lik } \\
\text { hidrokortizonlu kremler } \\
\text { uygulanmalıdır } \\
\end{array}$ & $\begin{array}{l}\text { - İlk } 24 \text { satte } 6 \text { saatte bir } 20 \mathrm{dk} \\
\text { sıcak uygulama yapılmalıdır. } \\
\text { Ancak topotecan ekstrava- } \\
\text { zasyonunda sıcak yerine soğuk } \\
\text { uygulama yapılır. } \\
\text { - Ekstravaze olan ilacın miktarı } \\
\text { fazla ise ialcın dağılımını } \\
\text { sağlamak için hafif masaj } \\
\text { yapılabilir }\end{array}$ \\
\hline
\end{tabular}


Tablo 1 (devam)

Vezikant İlaçların Ekstravasyonunda Önerilen Girişimler

\begin{tabular}{|c|c|c|}
\hline İlaç & Farmakolojik girişimler & Non-farmakolojik girişimler \\
\hline $\begin{array}{l}\text { Soyucular } \\
\text { Daunorubicin } \\
\text { Liposomal } \\
\text { Doxorubicin } \\
\text { Liposomal } \\
\text { Mitoxantrone }\end{array}$ & $\begin{array}{l}\text { - 5ml'nin altındaki ilaç ekstravazas- } \\
\text { yonlarda ilk } 7 \text { gün } 6 \text { saatte bir } \\
\text { topikal hidrokortizon uygulanır. } \\
\text { - 5ml'den fazla olanlarda topikal } \\
\text { DMSO ve \%1'lik hidrokortizon ilk } \\
\text { gün } 2 \text { saatte bir, takib eden } 14 \text { gün } \\
\text { süresince } 4 \text { defa/gün olarak } \\
\text { uygulanır. } \\
\text { - Mitoxantrone ekstravazasyonunda } \\
\text { ise 5-7 güne kadar her } 3 \text { saatte bir } \\
\text { topikal DMSO ve \%1'lik } \\
\text { hidrokortizon kullanılır. DMSO } \\
\text { pamukla bölgeye sürülür ve } \\
\text { kurutulur. Kanamaya ne-den } \\
\text { olmamak için kapatılmamalıdır. }\end{array}$ & $\begin{array}{l}\text { - İlk } 24 \text { saat her } 4 \text { saatte bir } 30 \\
\text { dk soğuk } \\
\text { yapılmalıdır. }\end{array}$ \\
\hline $\begin{array}{l}\text { Vezikantlar } \\
\text { Amsacrine } \\
\text { Dacarbazine } \\
\text { Dactinomycin } \\
\text { Daunorubicin } \\
\text { Doxorubicin } \\
\text { Epirubicin Idarubicin } \\
\text { Mitomycin } \\
\text { Streptozocin }\end{array}$ & $\begin{array}{l}\text { - Ekstravaze olan ilaç miktarı } \\
5 \text { ml'den az ise ilk } 24 \text { saat } 2 \text { saatte, } \\
\text { takibeden } 7 \text { günde her } 3 \text { saatte bir } \\
\% 1 \text { hidrokortizon krem ve topikal } \\
\text { DMSO uygulanır. } \\
\text { - } 5 \text { ml'den fazla olan ekstravazas- } \\
\text { yonlarda ise prosedürlere göre } \\
\text { insizyon yeri açılarak ilaç doku } \\
\text { dışına uzaklaştıllır } \\
\text { - Antrasiklin ekstravazasyonunu } \\
\text { takiben ilk 3-6 saat içinde IV ya da } \\
\text { S.C dexrazoxane uygu-lanabilir. } \\
\text { - Ekstravaze olan alana C vitamini } \\
\text { ve hyaluronidase etkili olduğu } \\
\text { tanımlansada ileri çalışmalara } \\
\text { gereksinim duyulmaktadır. } \\
\text { - Yapılan hayvan çalışmalarında } \\
\text { ekstravazasyona bağlı görülen } \\
\text { yaranın iyileşmesinde granülosit } \\
\text { stimüle edici faktörün S.C. yolla } \\
\text { uygulanmasının yararlı olduğu } \\
\text { görülmektedir. } \\
\text { - Mitomycin-C ekstravazasyonunda } \\
\text { DMSO ve sodium thiosulfat } \\
\text { kullanımı önerilmektedir }\end{array}$ & $\begin{array}{l}\text { - İlk } 24 \text { saat her } 4 \text { saatte bir } 30 \\
\text { dk soğuk uygulama } \\
\text { yapılmalıdır } \\
\text { - Günde iki defa uygulanan } \\
\text { hiperbarik oksijen tedavisi-nin } \\
\text { ekstravazasyon yarasının } \\
\text { iyileşme sürecinde etkili } \\
\text { olduğu tespit edilmiştir. }\end{array}$ \\
\hline
\end{tabular}


Tablo 1 (devam)

Vezikant İlaçların Ekstravasyonunda Önerilen Girişimler

\begin{tabular}{|c|c|c|}
\hline İlaç & Farmakolojik girişimler & Non-farmakolojik girişimler \\
\hline $\begin{array}{l}\text { Vezikantlar } \\
\text { Paclitaxel } \\
\text { Vinblastine } \\
\text { Vincristine } \\
\text { Vindesine } \\
\text { Vinorelbine }\end{array}$ & $\begin{array}{l}\text { - } 5 \text { ml'den az ekstravaze olan ilaçlarda } \\
\text { S.C. 1500U/ml hyaluronidase } \\
\text { enjeksiyonu, 5ml'den fazla olanlarda } \\
\text { ise bölgede insizyon açlarak ilacın } \\
\text { drene edilmesi önerilmektedir. } \\
\text { - Paclitaxel ekstravazasyonunda } \\
\% 1 \text { 'lik hidrokortizon krem her } 6 \\
\text { saatte bir 7 gün boyunca } \\
\text { uygulanmaktadır. }\end{array}$ & $\begin{array}{l}\text { - İlk } 24 \text { saat her } 6 \text { saatte bir } 20 \\
\text { dk sıcak uygulama yapılır. } \\
\text { - 5ml'den fazla olan } \\
\text { ekstravazasyonlarda ilacın } \\
\text { dağıllımını sağlamak için } \\
\text { bölgeye hafif masaj } \\
\text { uygulanabilir. }\end{array}$ \\
\hline $\begin{array}{l}\text { Vezikantlar } \\
\text { Busulfan } \\
\text { Carmustine } \\
\text { Treosulfan }\end{array}$ & $\begin{array}{l}\text { - } 5 \text { ml'den az ilaç } \begin{array}{c}\text { ekstra- } \\
\text { vazasyonlarında eritem } \\
\text { olduğu }\end{array} \\
\text { müddetçe \%1'lik hidrokortizon krem } \\
\text { uygulanır. } \\
\text { - } 5 \text { ml'den fazla ilaç ekstra- } \\
\text { vazasyonlarda ise prosedüre göre } \\
\text { insizyon açılarak ilaç derene } \\
\text { edilmelidir. }\end{array}$ & $\begin{array}{l}\text { - İlk } 24 \text { saat her } 4 \text { saatte bir } 30 \\
\text { dk soğuk uygulama } \\
\text { yapılmalidır. }\end{array}$ \\
\hline $\begin{array}{l}\text { Vezikantlar } \\
\text { Chlormethine } \\
\text { (Mustine) }\end{array}$ & $\begin{array}{l}\text { - } 5 \text { ml'den fazla olan ilaç ekstra- } \\
\text { vazasyonlarda \%3'lük sodium } \\
\text { thiosulphate } 1-3 \mathrm{ml} \text { S.C. uygulan- } \\
\text { malıdır. } \\
\text { - Eritem devam ettiği müddetçe } \\
\text { bölgeye \%1'lik hidrokortizon krem } \\
\text { uygulanabilir. }\end{array}$ & $\begin{array}{l}\text { - İlk } 24 \text { saat süresince her } 4 \\
\text { saatte bir soğuk uygulama } \\
\text { yap1lır }\end{array}$ \\
\hline
\end{tabular}

\section{KAYNAKLAR}

1. Ay, F.A. (2007). (Ed.) Ay, F.A. İlaç uygulamaları. İçinde: Temel Hemşirelik: Kavramlar, İlkeler, Uygulamalar, İstanbul Medikal Yayıncılık, İstanbul,348- 38

2. Türkiye Cumhuriyeti Sağlık Bakanlığı Hemşirelik Yönetmeliğinde Değişiklik Yapılmasına Dair Yönetmelik. http://www.resmigazete.gov.tr/eskiler/ 2011/04/20110159-5.htm. Erişim: 30 Aralik 2012.

3. Aslan, F.E. Olgun, N. (2010). (Eds.) Karadakovan, A. ve Aslan, F. E. Onkoloji. İçinde: Cerrahi ve Dahili
Hastalıklarda Bakım Nobel Tip Kitabevleri, Adana, s. 209-212

4. Lenhardt, R. Seybold, T. Kimberger, O. Stoiser, B. Sessler, D. (2002). Local warming and insertion of peripheral venous cannulas: single blinded prospective randomised controlled trial and single blinded randomised crossover trial, BMJ, 325: 59- 151

5. Elshamy, K.F. Mesbah, M.R. (2011). Effect of peer education intervention and procalcitonin detection on peripheral intravenous catheter-related blood stream infections and associated 
complications among selected patients at Mansoura University Hospitals, J Am Sci, 7(10): 38- 373

6. Guidelines for Prevention and Management of Chemotherapy Extravasation (2009). Surrey, West Sussex and Hampshire Cancer Network, Version:4, p.1-12 https://bibliomed.bib.uniud.it/links/c-1infermieristica/calcolo-applicato-allaterapia-

famacologica/swsh_network_chemoth erapy_extravasation_guidelines_1.09. pdf. Erişim: 22.09.2014.

7. Hadaway, L.C. (2004). Preventing and managing peripheral extravasation, Nursing, 2009, 26- 27

8. Infusion Nurses Society (2011). Infusion Nursing Standarts of Practice. J Infus Nurs. 34(1): 25-30,37-15, 4449, 7,65-72,18-89.

9. Jacobson, A.F. Winslow, E.H. (2005). Variables influencing intravenous catheter insertion difficulty and failure: an analysis of 339 intravenous catheter inserions. Heart\&Lung, 34(5): 345-360

10. O'Grady, N.P. Alexander, M. Burns, L.A. Dellinger, P. Garland, J.O. Heard, S. Lipsett, P.A. Masur, H. Mermel, L.A. Pearson, M.L. Raad, II. Randolph, A. Rupp, M.E. Saint, S. and the Healthcare Infection Control Practices Advisory Committee (2011). Central of Disease Control Guidelines for The Prevention of Intravascular Catheter-Related Infections. U.S. Department of Health and Human Services, U.S.A. p.20-26

11. Royal King College of Nursing Standards for Infusion Therapy (2010). Third Edition, London, p.720,60-65

12. The National Extravasation Information Service (2005). Chemotherapy Executive Group at St Chad's Unit, City Hospital Birmingham, UK.

13. Woscan Chemotherapy Extravasation Guideline (2009). Chemotherapy
Extravasation in Practice, Woscan Cancer Nursing and Pharmacy Group, p. $1-24$

14. Schulmeister, L. (2010). Preventing and managing vesicant chemotherapy extravasations, J Supp Oncol, 8: 21223

15. Ener, R.A. Meglathery, S.B. Styler, M. (2004). Extravasation of systemic hematooncological therapies. Anns Oncol, 3(6): 858- 88

16. Fidalgo, J.A. Fabregat, L.G. Cervantes, A. et al. (2012). Management of Chemotherapy Ekstravasation: ESMO-EONS Clinical Practice Guidelines. Anns Oncol, 23(7):167-14

17. Ingram, P. Lavery, I. (2005). Peripheral intravenous therapy: Key risks and implications for practice, Nurs Standart. 19(46): 55- 9

18. McCallum, L. (2012). Care of Peripheral Venous Cannula Sites. Nursing Times, 108(34/35): 12- 3

19. Schulmeister, L. (2008). Managing vesicant extravasations, The Oncologist, 13: 284- 288

20. Waitt, C. Waitt, P.Pirmohamed, M. (2004). Intravenous therapy, Postgrad Med J, 80:1- 6

21. Franklin, B.D. Deelchand, V. Cooke, M. Holmes, A. Vincent, C. (2012). The safe insertion of peripheral intravenous catheters: a mixed methods descriptive study of the availability of the equipment needed, Antimicrobial Resistance and Infection Control, 1(3): 1-6

22. Moureau, N. (2009). Preventing peripheral intravenous line infections: Recommendations for healthcare facilities, JAVA, 14(4): 187- 191

23. Flippo, L.P. (2011). Clinical evaluation of the sorbaview shield securement device used on peripheral intravenous catheters in the acute care setting, JAVA, 16(2): 1- 8

24. Maki, D.G. Kluger, D.M. Crnich, C.J. (2006). The risk of bloodstream infection in adults with different 
1ntravascular devices: A systematic review of 200 published prospective studies. Mayo Clin Proc. 81(9): 139111

25. Karagözoğlu， Ş. (2001). Intravenöz siv1 tedavisi komplikasyonu olarak gelişen tromboflebitte hemşirelik bakımı ve sicak-soğuk uygulamanın yeri, Cumhuriyet Üniversitesi Hemşirelik Yüksek Okulu Dergisi, 5(1): 18- 26

26. Rickard, C.M. Webster, J. Wallis, C.M. Marsh, N. McGrail, M.R. French, V. Foster, L. Gallagher, P. Gowardman, J.R. Zhang, L. McClymont, A. Whitby, M. (2012). Routine versus clinically indicated replecament of peripheral intravenous catheters: A randomised controlled equivalence trial. Lancet, 380:11-1074

27. Çelik, Z. Anıl, C. (2004). İntravenöz uygulama komplikasyonları, Güncel Gastroenteroloji. 8(2): 38- 165

28. Centers for Disease Control and Prevention Morbidity and Mortality Weekly Report. (2002). Guidelines for the prevention of intravascular catheter-related infections, 51; RR 10

29. Yan, N. (2010). Peripheral intravenous catheter: Phlebitic risks and prevention, Stanford Nurse, Spring: 318

30. Schulmeister, L.C. (2011). (Ed.) Olver, I. N. Extravasation. In: The MASCC Textbook of Cancer Supportive Care and Survivorship, doi:10.1007/978- 1-4159-1225-1-34

31. Schrijvers, D.L. (2003). Extravasation: A dreaded complication of chemotheraphy, Annals Oncol, 14(3): 26-30

32. Gündoğdu, F. (2007). Ekstravazasyon. İçinde: Onkoloji Hemşireliği Derneği Kemoterapi Hemşireliği Kurs Kitabı, Ankara, s. 37- 45

33. Aktasi, S. Toklu, A. S. Olgac, V. (2000). Hyerbaric oxygen therapy in adriamycin extravasation: A experimental animal study, Ann Plast Surg, 45:167-11
34. Bilge, N.Ş. Dündar, E. Mutlu, F. Gülbaş, Z. (2011). Erythropoietin improves the healing of skin necrosis resulting from doxorubicin extravasation in a rat model, Current Therapeutic Research, 72(4): 115- 30

35. Chanes, C.C. Pedreira, M.G. Gutierrez, M.G.R. (2012). Antineoplastic agents extravasation from peripheral intravenous line in children: A simple strategy for a safer nursing care, Eur J Oncol Nurs, 16:125

36. Disa, J.J. Chang, R.R. Mucci, S.J. Goldberg, N.H. (1998). Prevention of adriamycininduced full thickness skin loss using hyaluronidase infiltration, Plast Reconstr Surg, 101: 370-4 (abstract)

37. Langer, S.W. Sehested, M. Jensen, P.B. (2000). Treatment of anthracycline extravasation with dexrazoxane, Clin Cancer Res, 6: 3680- 3618 (abstract)

38. Schulmeister, L. (2011). Vesicant chemo-therapy extravasation management, British Journal of Nursing, 20: 6- 12

39. Vargel, I. Erdem, A. Ertoy, D. Pinar, A. Erk, Y. Altundağ, M.K. Güllü, I. (2002). Effects of growth factors on doxorubicin-1nduced skin necrosis: documentation of histomorphological alteration and early ttreatment by GMCSF and G-CSF, Ann Plast Surg 49: 646-9 